\title{
Synthesis of Chitosan / Zinc Oxide Nanoparticles Stabilized by Chitosan via Microwave Heating
}

\author{
Nurul Amira Ahmad Yusof*, Norashikin Mat Zain, Norlin Pauzi \\ Faculty of Chemical \& Natural Resources Engineering, Universiti Malaysia Pahang, Highway Tun \\ Razak, 26300 Kuantan, Pahang, Malaysia
}

Received: 1st October 2018; Revised: 14 th February 2019; Accepted: $15^{\text {th }}$ February 2019; Available online: 30th April 2019; Published regularly: 1st August 2019

\begin{abstract}
Nowadays, zinc oxide $(\mathrm{ZnO})$ has attracted attention in research and development because of its remarkable antibacterial properties. Chitosan/ZnO nanoparticles were successfully synthesized via microwave heating. The objectives of this work were to investigate the effect of stabilizer, power heating and time heating on size of chitosan/ZnO nanoparticles and to determine antibacterial activity against pathogenic bacteria, where chitosan was used as a stabilizing agent. Chitosan/ZnO nanoparticles were analyzed by Fourier Transform Infra Red (FTIR), X-ray Diffraction (XRD), Field Emission Scanning Electron Microscopy (FESEM), and Zetasizer instrument. The power heating and time heating were varied from 400 to $800 \mathrm{Watt}$ and 4 to 8 minutes, respectively. The presence of chitosan has role on preventing the nanoparticles from agglomeration by producing a milky solution of chitosan/ZnO nanoparticles without any suspensions. The increase of power and time heating improved the size of nanoparticles. The peak in FTIR spectrum at around $427 \mathrm{~cm}^{-1}$ was confirmed the existence of the $\mathrm{ZnO}$ phase. XRD patterns showed that the chitosan/ZnO nanoparticles materials were pure phase with average crystalline size is $130 \mathrm{~nm}$. FESEM revealed that chitosan/ZnO nanoparticles were uniformly distributed with the mean value of size is $70 \mathrm{~nm}$ and spherical shaped. Further impact of power and time heating on the size of the chitosan/ZnO nanoparticles can be shown by a nanoparticles size distribution with the average of 30 to $90 \mathrm{~nm}$. The results showed that chitosan/ZnO nanoparticles have displayed an antibacterial inhibition zone against Gram-positive $S$. aureus and Gram-negative E. coli which 16.0 and $13.3 \mathrm{~mm}$, respectively. Chitosan/ZnO nanoparticles were synthesized in this work presented have potential application to prevent bacterial infections. Copyright (C) 2019 BCREC Group. All rights reserved
\end{abstract}

Keywords: ZnO Nanoparticles; Chitosan; Microwave Heating; Stabilizer; Antibacterial.

How to Cite: Yusof, N.A.A., Zain, N.M., Pauzi, N. (2019). Synthesis of Chitosan/Zinc Oxide Nanoparticles Stabilized by Chitosan via Microwave Heating. Bulletin of Chemical Reaction Engineering \& Catalysis, 14(2): 450-458 (doi:10.9767/bcrec.14.2.3319.450-458)

Permalink/DOI: https://doi.org/10.9767/bcrec.14.2.3319.450-458

\section{Introduction}

Zinc oxide $(\mathrm{ZnO})$ has gained the attention of the researches due to its potential properties in the application of electronic and optical device

* Corresponding Author.

E-mail: shikin@ump.edu.my (N.A.A. Yusof);

Telp: +609- 5492930, Fax: +609-5492889
[1,2]. Until now, many conventional methods such as hydrothermal, sol-gel or precipitation method have been developed for the production of $\mathrm{ZnO}$ nanoparticles. However, these methods show a difficulty in controlling the size of nanoparticles [3].

This work is developed the $\mathrm{ZnO}$ nanoparticles using microwave-assisted as it was offered 
the best possibility of being environmentally friendly and an economic by consuming short period of processing [4,5]. Microwave-assisted synthesis is the best method compared to the conventional method such as hydrothermal and sol-gel method [6], as it provides higher reaction rates, faster volumetric heating, higher selectivity and higher yields of products [7]. Consider the advantage of this method, the microwave heating was adopted in this work to synthesis chitosan/ZnO nanoparticles. Previous studies by Thirumavalavan et al. [8], Rajendran \& Sivalingam [9], and Barreto et al. [10], used zinc nitrate hexahydrate $\left(\mathrm{Zn}\left(\mathrm{NO}_{3}\right)_{2} .6 \mathrm{H}_{2} \mathrm{O}\right)$ as a metal salt with chitosan as stabilizing agent to synthesis chitosan/ZnO nanoparticles using facile preparation, hydrothermal process and ultrasonic treatment, respectively. However, the used of $\mathrm{Zn}\left(\mathrm{NO}_{3}\right)_{2} .6 \mathrm{H}_{2} \mathrm{O}$ as a metal salt was not found in the formation of chitosan/ZnO nanoparticles using microwave heating method. Most of the previous studies used either zinc acetate dihydrate $[11,12]$ or commercial $\mathrm{ZnO}[10,13-16]$ as metal salt for microwave heating method. There were no studies related to the formation of chitosan/ZnO nanoparticles using chitosan as stabilizer at selected power and time heating.

Chitosan as a natural copolymer plays important role in stabilizing the nanoparticles by coating the surface [17], and prevent the nanoparticles from oxidizing to the surrounding as their structure that almost resembles to the cellulose [18]. In this work, the chitosan was prepared in solution form as it is possessing excellent biocompatibility and ease process. Plus, they also tend to swell and dehydrate depending on composition and environment [19].

A reason of using chitosan compared to other conventional stabilizing agents is that it possesses good antibacterial properties [20]. Plus, there appear to be no published studies on the synthesis of chitosan/ZnO nanoparticles using chitosan with microwave heating at selected power and time heating. The synthesized chitosan/ZnO nanoparticles were expected to be achieved in only a few minutes. Herein, the impact of chitosan/ZnO nanoparticles also been tested on Gram-positive and Gram-negative bacteria.

\section{Materials and Methods}

All chemicals used in this experiment were of analytical grade and were used without further purification. Zinc nitrate hexahydrate $\left(\mathrm{Zn}\left(\mathrm{NO}_{3}\right)_{2} .6 \mathrm{H}_{2} \mathrm{O}, 98 \%\right.$, Aldrich) and sodium hydroxide (NaOH, 98.9\%, Bendosen) were used as the zinc cation and hydroxide agent, respectively. Acetic acid was used to dilute chitosan flakes into solution. Chitosan acts as stabilizing agent and distilled water is used for the preparation of solutions.

\subsection{Synthesis of Chitosan/ZnO Nanoparticles}

Chitosan solution $(1.0 \% \mathrm{w} / \mathrm{v})$ was prepared by dissolving chitosan in $1 \% \mathrm{v} / \mathrm{v}$ of an acetic acid solution. After the fully dissolved, $50 \mathrm{~mL}$ of $\mathrm{Zn}\left(\mathrm{NO}_{3}\right)_{2} \cdot 6 \mathrm{H}_{2} \mathrm{O}$ and $50 \mathrm{~mL}$ of $\mathrm{NaOH}$ were mixed with $5 \mathrm{~mL}$ of chitosan. Following the reduction process of zinc ions, the color of the solution turns to a milky solution. After the reduction process is complete (when the color remains unchanged), the products were then subjected to microwave irradiation at the power of irradiation of 400,600 , and 800 watt for the selected time of irradiation of 4,6 , and 8 minutes.

\subsection{Characterization of Chitosan/ZnO Nano- particles}

Chitosan/ZnO nanoparticles were characterized by FTIR, XRD, FESEM, and Zetasizer instrument. The result of FTIR, XRD, and FESEM discuss the effect of stabilizer, while the result of Zetasizer analysis explains on the effect of time and power heating. After that, the nanoparticles were tested for antibacterial activity using Gram-positive S. aureus and Gram-negative $E$. coli bacteria.

\subsubsection{Fourier Transform Infrared Spectroscopy (FTIR)}

The FTIR spectra are the best analysis to screen and optimized the functional group of nanoparticles using FTIR model: iD7 Attenuated Total Reflectance (ATR) Nicolet iS5 Spectrometer (Thermo Fisher, USA). The FTIR spectra of $\mathrm{ZnO}$ nanoparticles which was analyzed on ATR diamond crystal was compared with the FTIR spectra of chitosan and water. The FTIR spectra were obtained at the room temperature at the wavelength from $400 \mathrm{~cm}^{-1}$ to $4000 \mathrm{~cm}^{-1}$. FTIR was performed using OMNIC software with an average of 32 scans. The spectral resolution used for the recording of the IR spectra was $2 \mathrm{~cm}^{-1}$.

\subsubsection{X-ray Powder Diffraction (XRD)}

XRD diffraction was used to measure the various crystalline form of nanoparticles. XRD patterns recorded on a Philips PW 3050/10 model. The samples were recorded on a Philips X-Pert MMP diffractometer. The diffractometer 
was controlled and operated by a PC computer with the programs $\mathrm{P}$ Rofit and used a MoK (source with wavelength $0.70930 \AA$, operating with Mo-tube radiation at $50 \mathrm{kV}$ and $40 \mathrm{~mA}$.).

\subsubsection{Field Emission Scanning Electron Micro- scope (FESEM)}

The surface morphology of the nanoparticles was examined by FESEM instrument operated at an accelerating voltage at $5 \mathrm{kV}$ using a JSM$7800 \mathrm{~F}$ (JEOL, USA) field emission scanning electron microscopy (FESEM).

\subsubsection{Particles Size and Zeta Potential Analysis}

The mean particle size and zeta potential of $\mathrm{ZnO}$ nanoparticle were measured using a Zetasizer instrument (Model ZEM5002, Malvern Instruments Ltd, Malvern, UK) using UV Grade cuvettes after treatment in an ultrasonic water bath (Model FB11012, Fisherbrand) for 30 min to break up any aggregates present.

\subsection{Zone of Inhibition Testing}

A disk of filter papers was impregnated with chitosan/ZnO nanoparticles and was put onto tryptone soya agar (TSA) plates that had been spread with $100 \mu \mathrm{L}$ of the bacterium. The plates were then incubated in the incubator at $37{ }^{\circ} \mathrm{C}$ overnight. Triplicate experiments were carried out for each sample. The diameter of inhibition zone was measured using a ruler to the nearest millimeter. This procedure was applied for a zone of inhibition testing with testing with $S$. aureus and E. coli.

\section{Results and Discussion}

\subsection{Synthesis of Chitosan/ZnO Nanoparticles}

The chitosan/ZnO nanoparticles was turn from colorless to a milky solution as showed in Figure 1. The first attempt has been carried out to synthesis $\mathrm{ZnO}$ nanoparticles by reduc-

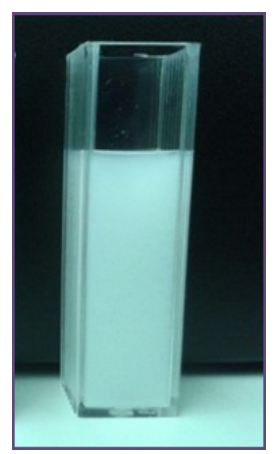

Figure 1. Chitosan/ZnO nanoparticles solution tion of zinc nitrate with sodium hydroxide $(\mathrm{NaOH})$ only without a stabilizing agent. There was an agglomeration occurred and nonhomogenous solution was obtained.

This phenomenon can be explained which the addition of zinc nitrate to an initial solution of $\mathrm{NaOH}$ produces a milky precursor solution. This is the first stage of the zinc nitrate reduction reaction, which is dissociated into $\mathrm{Zn}^{2+}$ and $\mathrm{NO}_{3}^{-}$ions. Then, after a few minutes of stirring, the suspensions were formed in the solution because of the agglomeration process. When there is no coverage of the stabilizing agent on the nanoparticles surface, the agglomeration started to form [21]. If the reduction process precedes the interaction, the nanoparticles growth cannot be properly controlled. Agglomerates of $\mathrm{Zn}^{2+}$ ions formed are called clusters.

Mahmudin et al. [22] were stated that the preparation of nanoparticles in solution should consist of reduction of the ions and stable polymer of the metal. This reveals that the needs of stabilizer are important in the synthesized of $\mathrm{ZnO}$ nanoparticles. In this study, chitosan was used as a stabilizing agent and reacts with $\mathrm{H}^{+}$ to produce protonized chitosan with $\mathrm{NH}^{3+}$ functional groups. Then, $\mathrm{NaOH}$ solution was acts as a hydroxide agent, it will produce the white precipitate of chitosan/ZnO nanoparticles. The exposure of solution to the microwave power dissolves the precipitate into the supersaturated aqueous solution [23]. A formation of the colloids was revealed by coloration of the solution. The solution was spontaneously changed to a milky solution without any suspensions upon mixing with the protonized chitosan.

\subsubsection{Effect of Stabilizer on Chitosan/ZnO Na- noparticles}

Chitosan/ZnO nanoparticles have a compelling tendency to flocculate due to their van der walls forces. However, the agglomeration can be hindered by introducing a repulsive force between the particles. In this light, the use of a stabilizer as a repulsive force came into the picture. The use of chitosan as a stabilizer was reported elsewhere [24]. Chitosan contributed the steric hindrance to stabilize the nanoparticles which the amino group presence in its polycationic structure activates steric hindrance, thus ensuring strong stability over long [25].

Remarkably, chitosan possesses similar ability as proteins and manipulations of its properties have not been fully extended for numerous applications. Chitosan is accessible for cross-linking through its boundless amino 
group and its cationic features allowing the ionic crosslinking to take place with multivalent elements. The most promising features of chitosan are its solubility in aqueous acidic solutions [5]. The description of chitosan agrees with the aims of the research to manufacture a readily biocompatible and nontoxic chitosan capped $\mathrm{ZnO}$ nanoparticles.

\subsubsection{FTIR analysis}

FTIR quantitative analysis was performed to trace any impurities and to determine the functional groups species of chitosan/ZnO nanoparticles. The absorption spectra all samples were identified and shown in Figure 2. The spectrum of synthesized chitosan/ZnO nanoparticles present a acute band below $600 \mathrm{~cm}^{-1}$ which related to the stretching vibration of $\mathrm{Zn}$ $\mathrm{O}$ bond and broad peak between 3341 and 2912 $\mathrm{cm}^{-1}$ associated to the vibration of $\mathrm{O}-\mathrm{H}$ bond of the chemosorbed water. Besides that, the absorption bands centered at about 1981, 1640, 1556 , and $1375 \mathrm{~cm}^{-1}$ that exist on all the cases of FTIR spectrums can be designated to the O$\mathrm{H}$ stretching vibrations, $\mathrm{CO}_{2}$ mode, and asymmetric and symmetric $\mathrm{C}=\mathrm{O}$ stretching modes, respectively [26]. As mentioned by Pandiselvi \& Thambidurai [27], a broad absorption peak for the vibration of the O-Zn-O group was in the range of 580 to $400 \mathrm{~cm}^{-1}$. Thus, in comparison with the FTIR spectrum of chitosan, the new

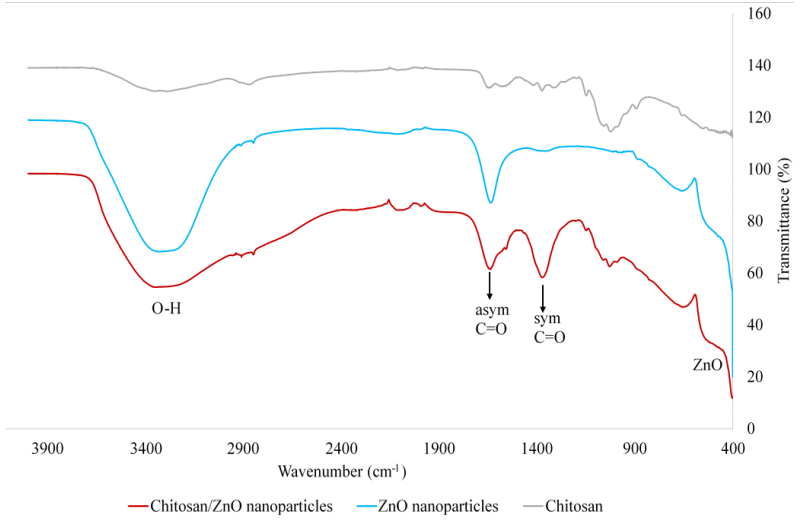

Figure 2. FTIR spectra of chitosan/ZnO nanoparticles. peak was displayed at $427 \mathrm{~cm}^{-1}$ represented the stretching mode of $\mathrm{ZnO}$ as the result attained in this analysis are in compromise with past research $[13,23,28]$.

\subsubsection{XRD analysis}

This analysis is to analyzed the size of various crystallite forms of nanoparticles. Figure 3 shows the patterns of all samples. It was proved from the patterns that the chitosan/ZnO nanoparticles were well crystalline ones. All peaks of XRD spectra were compared with the standard peaks in JCPDS files resulting in excellent matching all samples. Furthermore, there are no impurities were observed in the characteristic peaks.

By applying the Debye Scherrer formula, the average size of $\mathrm{ZnO}$ nanoparticles without chitosan was calculated to be $327 \mathrm{~nm}$. This is because of interparticle attraction which small particles in a liquid have the tendency to aggregate without the presence of a stabilizer [10]. This is the reason for selection of why chitosan as the stabilizing polymer in order to prevent aggregation and sedimentation.

The average crystallite size of the chitosan/ZnO nanoparticles calculated using the Debye Scherrer formula (Equation (1)).

$$
D=\frac{0.9 \lambda}{\beta \cos \theta}
$$

Where, $\lambda$ represents the X-ray wavelength of $\mathrm{Cu}-\mathrm{Ka}$ radiation source (1.5418 $\AA$ ); $\beta$ is the full

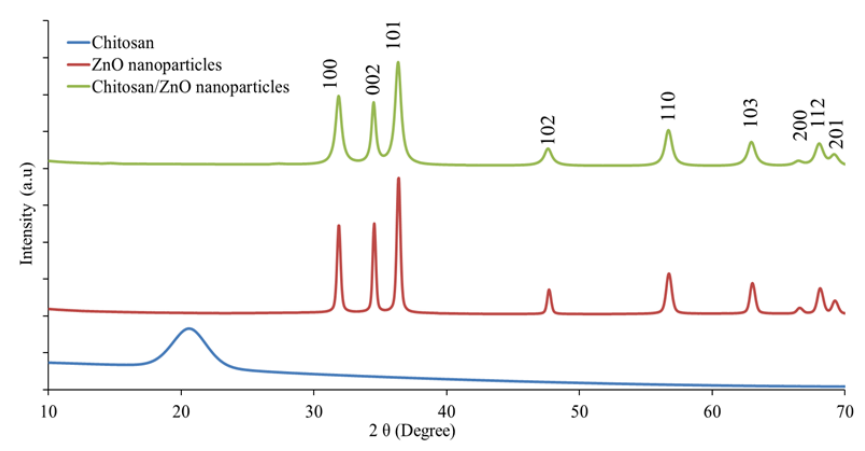

Figure 3. XRD powder pattern of chitosan/ZnO nanoparticles

Table 1. The average size of chitosan/ZnO nanoparticles and $\mathrm{ZnO}$ nanoparticles by XRD measurement

\begin{tabular}{lccccc}
\hline \multirow{2}{*}{ Sample name } & $2 \theta\left(^{\circ}\right)$ & FHWM & $\begin{array}{c}\text { Average crys- } \\
\text { talline size }\end{array}$ & \multicolumn{2}{c}{ Lattice parameter $(\AA)$} \\
\cline { 5 - 6 } & & $(\mathrm{n})$ & 327 & 3.2540 & 5.2200 \\
\hline ZnO nanoparticles & 36.338 & 0.2952 & 327 & 3.2540 & 5.2200 \\
\hline
\end{tabular}


width at half maximum (FWHM) intensity of the diffraction peak located at $2 \theta$; and $\theta$ is the Bragg angle. The average crystalline size of chitosan/ZnO nanoparticles is found to be 130 $\mathrm{nm}$ at $36.30^{\circ}$. It was evident that the presence of chitosan as a stabilizer reduced the agglomeration rate in the synthesis of $\mathrm{ZnO}$ nanoparticles, thus reduced the crystallite size of nanoparticles.

\subsubsection{FESEM analysis}

The FESEM image of chitosan/ZnO and $\mathrm{ZnO}$ nanoparticles covered by platinum is presented in Figure 4. The synthesized chitosan/ZnO nanoparticles are presented in Figure 4 (b) were uniformly distributed and most particles were from 50.6 to $61.7 \mathrm{~nm}$ with the mean value of $56.0 \mathrm{~nm}$. While, as evident from Figure 4 (a),
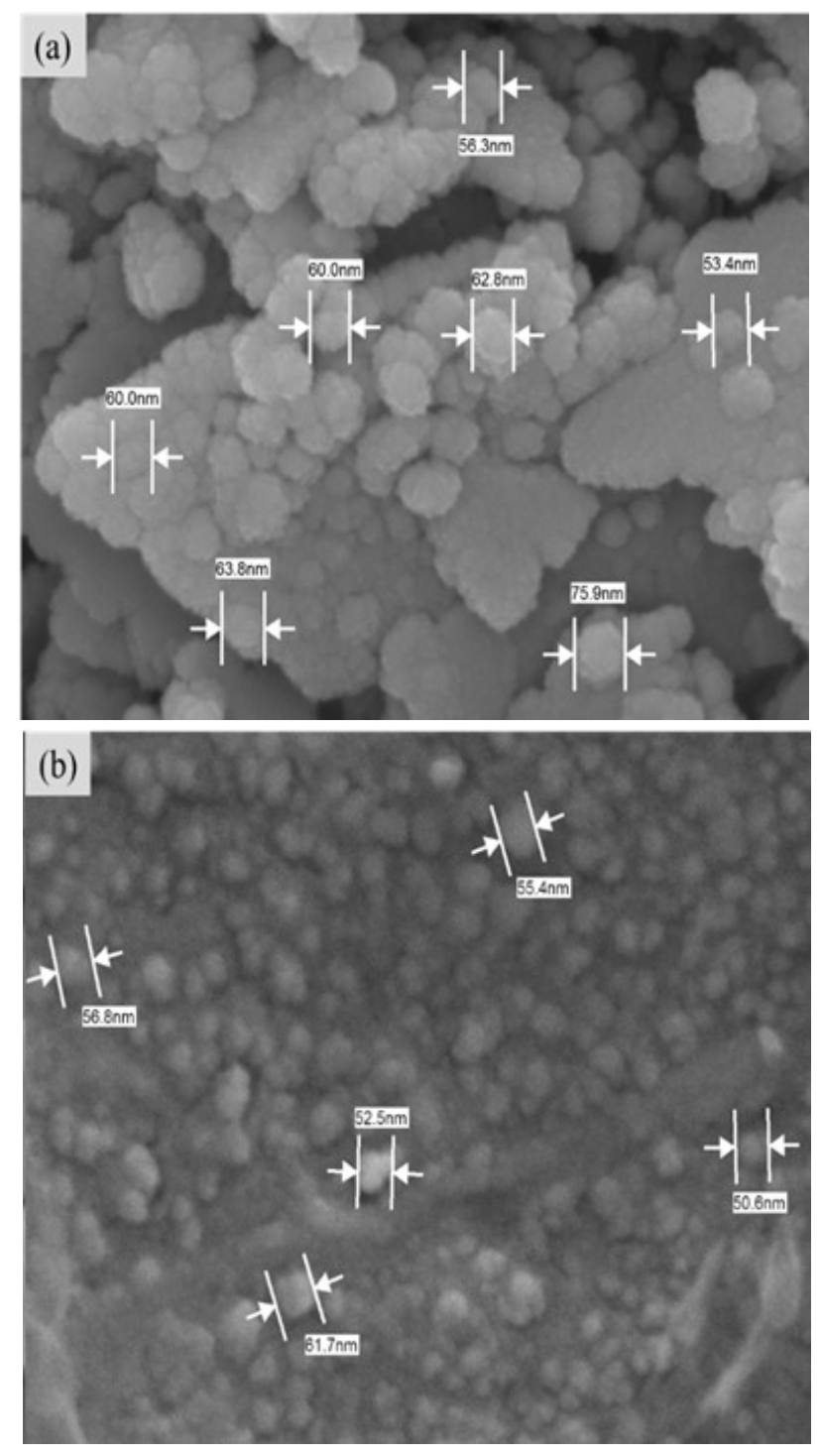

Figure 4. FESEM image of (a) $\mathrm{ZnO}$ nanoparticles and (b) chitosan/ZnO nanoparticles. the $\mathrm{ZnO}$ nanoparticles were agglomerated and the particles-shaped were transformed into sheet-shaped as the particles were attached to each other. The absence of stabilizing agent formed the non-discrete nanoscale particles with the floc-like structures of $\mathrm{ZnO}$ nanoparticles [29]. Similar results have been shown by Singh \& Surinder [16], which the $\mathrm{ZnO}$ nanoparticles produced by the spray dried method were coagulated and rod type with average size was $215.4 \mathrm{~nm}$. However, the presence of chitosan as a stabilizer in their study has reduced the size of $\mathrm{ZnO}$ nanoparticles to $167.2 \mathrm{~nm}$.

3.1.5 Mean particle size distribution of chitosan/ZnO nanoparticles under microwave heating

It is a fact that the microwave heating has a major impact on citizen/ZnO nanoparticles size distribution. The mean particle size of chitosan/ZnO nanoparticles prepared at different power and time heating is in the range of 30 to 90nm in size as shown in Figures 5 and 6, respectively. Chitosan/ZnO nanoparticles was synthesized under different heating power which from 400 to $800 \mathrm{~W}$. As increasing in heating power tends to increase the tempera-

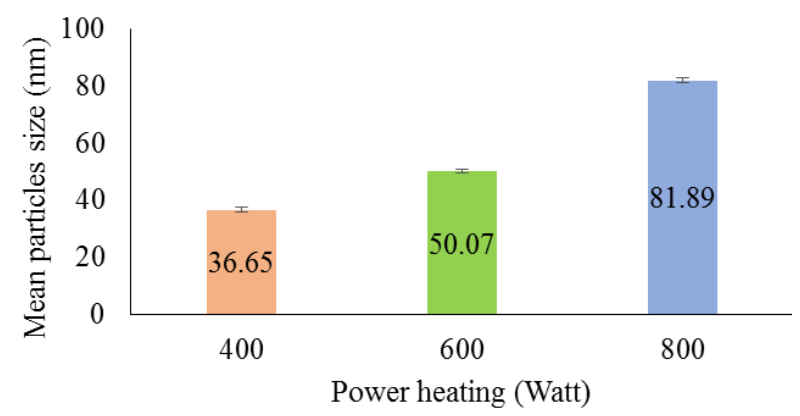

Figure 5. Histogram of the chitosan/ZnO nanoparticles size distribution prepared under different power heating.

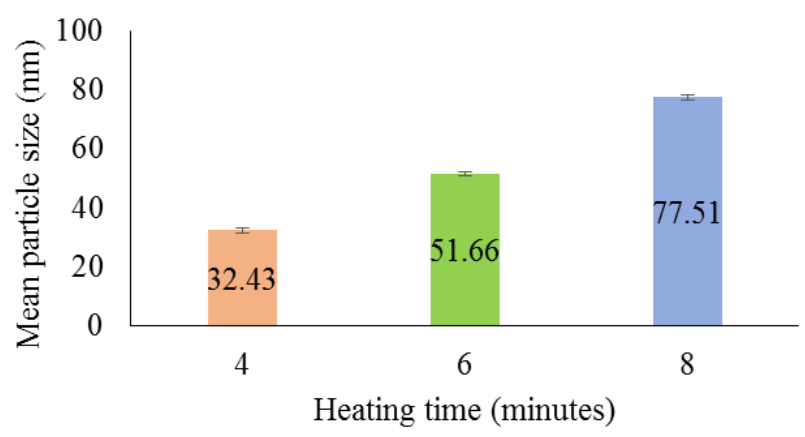

Figure 6. Histogram of the chitosan/ $\mathrm{ZnO}$ nanoparticles size distribution prepared under different time heating. 
ture rate in chitosan/ $\mathrm{ZnO}$ nanoparticles solution. From the result in Figure 5, the particle size distribution of chitosan/ZnO nanoparticles was increased as the heating power increased which from 30 to $80 \mathrm{~nm}$.

Nanoparticles synthesized by conventional heat transfer tend to be larger than the one produced by microwave heating. When the chitosan/ZnO nanoparticles were produced by microwave heating, the dipoles tends to align in the direction of the applied electric field; in such a way energy is lost in the form of heat, through dielectric loss and molecular friction. Also, microwave heating produces efficient internal heating, creating numerous "hot spots" which could trigger multiple nucleation events throughout the solution. However, increasing in temperature rate will cause to coagulation and shorten the period growth [30]. This shows that power heating give an impact to the chitosan/ZnO nanoparticles.

Figure 6 revealed that the increase of the heating time from $4 \mathrm{~min}$ to $8 \mathrm{~min}$ increases the size of nanoparticles. The temperature of chitosan/ZnO nanoparticles samples was risen rapidly during the process and drops gradually after the process. Wojnarowicz et al. [31] stated that increasing the heating time could increase the temperature of chitosan/ZnO nanoparticles which may be reached up to the boiling point of the solution.

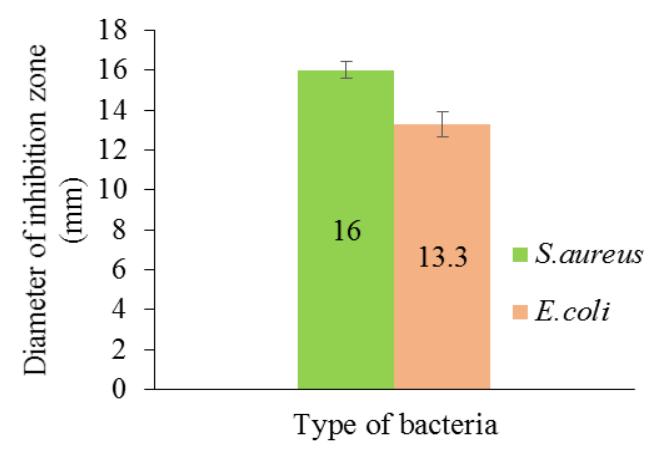

Figure 7. Inhibition zone testing of chitosan/ZnO nanoparticles against bacteria
In this study, a vapor was observed from chitosan/ZnO nanoparticles when the heating time was increased. This resulted because the solution is boiled up to the boiling point. During the boiling time, the metal nanoparticles isgrow so that the average size of chitosan/ZnO nanoparticles is increased as the heating time increase [30]. Then, heating time also has angive an effect on the formation of particles.

\subsubsection{Zeta potential analysis}

The stability of nanoparticles also can be determined by the zeta surface charge. Suspensions of $\mathrm{ZnO}$ are stable in the neutral $\mathrm{pH}$ range [32]. The zeta potential was found to be -29.6 $\mathrm{mV}$ for $\mathrm{ZnO}$ nanoparticles treated at $800 \mathrm{~W}$ for 6 minutes of heating time which indicated the higher degrees of stability. It has been reported that the value of zeta potential within the range of $-30 \mathrm{mV}$ to $+30 \mathrm{mV}$ represent the stable nanoparticles with low possibility of agglomeration [34-36].

The result suggested that the size and zeta potential vary with the applied conditions for heating which help in fast reduction of $\mathrm{ZnO}$ nanoparticles and chitosan. These results support the heating effect to form $\mathrm{ZnO}$ nanoparticles with varying size and higher stability due to the chitosan adsorption as donor and nanoparticles surface as accepter. The negative values obtained for zeta potential indicated that the nanoparticles surface was negatively charged. Also, the stability of nanoparticles was influenced by the size of nanoparticles. Nanoparticles with large surface area give the more negative charge on nanoparticles [37]. The increase in particle size can be attributed to aggregation of $\mathrm{ZnO}$ nanoparticles.

Yamamoto [38] and Sirelkhatim et al. [39] were stated that the nanoparticles with a stable surface charged potential and smallest size below $70 \mathrm{~nm}$ would give the best antibacterial effect towards pathogenic bacteria. They were concluded that the decreasing in size would increase the antibacterial activity of nanoparticles. Thus, the chitosan/ZnO nanoparticles syn-

Table 2. Zeta potential of synthesized chitosan/ZnO nanoparticles by microwave-assisted method.

\begin{tabular}{cccccc}
\hline Samples & $\begin{array}{c}\text { Concentration of zinc } \\
\text { salt (M) }\end{array}$ & $\begin{array}{c}\text { Concentration of } \\
\text { chitosan(\% w/v) }\end{array}$ & $\begin{array}{c}\text { Power } \\
\text { (watt) }\end{array}$ & $\begin{array}{c}\text { Time } \\
\text { (minutes) }\end{array}$ & $\begin{array}{c}\text { Zeta potential } \\
(\mathrm{mV})\end{array}$ \\
\hline 1 & 0.1 & 1.0 & 400 & 6 & -20.9 \\
2 & 0.1 & 1.0 & 600 & 6 & -27.8 \\
3 & 0.1 & 1.0 & 800 & 6 & -29.6 \\
4 & 0.1 & 1.0 & 600 & 4 & -25.6 \\
5 & 0.1 & 1.0 & 600 & 8 & -27.2 \\
\hline
\end{tabular}


thesized at 600 watt of power heating and 6 minutes of time heating was chosen to be further study for the antibacterial properties. The size of this sample is $51.66 \mathrm{~nm}$ with $-27.1 \mathrm{mV}$ of surface charged potential which considered being the most stable chitosan/ZnO nanoparticles compared to the others nanoparticles.

\subsubsection{Antibacterial activity of chitosan/ZnO na- noparticles}

The antibacterial activity of chitosan/ZnO nanoparticles was presented in Figure 7. Chitosan/ZnO nanoparticles showed an inhibition towards $S$. aureus and $E$. coli of the tested microorganism. The larger zone was seen at $S$. aureus culture which is $16 \mathrm{~mm}$ compared to the $E$. coli culture with $13.3 \mathrm{~mm}$ of inhibition zone. Based on the results obtained, it can be suggested that Gram-negative bacteria is more resistance to chitosan/ZnO nanoparticles compared to the growth of Gram-positive bacteria. This fact was supported by Jin et al. [40] and Premanathan et al. [41] that chitosan/ZnO nanoparticles showed an efficient antibacterial properties on Gram-positive than on Gramnegative bacteria because there is a major difference in the cell wall of bacteria could determine the resistance of bacteria. S. aureus are composed of thick wall with size $20-80 \mathrm{~nm}$ as surface layer. Meanwhile, E. coli are composed of thin layer below $10 \mathrm{~nm}$ [42].

Farouk et al. [11] has studied the effect of $\mathrm{ZnO}$ and chitosan/ZnO nanoparticles towards a Gram-negative bacterium, and a Grampositive. According to Padmavathy and Vijayaraghavan [44], the chitosan/ZnO nanoparticles have an abrasive surface texture which influences the antibacterial mechanism, which in sequence destroys the bacterial membrane. The results show that the presence of chitosan has enhanced the antibacterial properties of $\mathrm{ZnO}$ nanoparticles [43].

\section{Conclusions}

In conclusion, the chitosan/ZnO nanoparticles was synthesized by microwave-assisted method by using chitosan as a stabilizing agent. The presence of a new peak at around $427 \mathrm{~cm}^{-1}$ in the FTIR spectrum confirmed the existence of the $\mathrm{ZnO}$ phase. XRD patterns show that the chitosan/ZnO nanoparticles materials are pure phase with good crystallinity and completely matched the standard peaks. FESEM revealed that chitosan/ZnO nanoparticles were uniformly distributed in the range of 50.6 to $61.7 \mathrm{~nm}$ with spherical shaped. The increasing power and heating time resulted in the increas- ing of the size due to the nucleation of nanoparticles. Surface zeta potential was negative for all the nanoparticles. The results showed that chitosan/ZnO nanoparticles have displayed an antibacterial inhibition zone against S. aureus and E. coli which 16.0 and $13.3 \mathrm{~mm}$, respectively.

\section{Acknowledgments}

Nurul Amira Ahmad Yusof would like to thank the Ministry of Education, Malaysia, and Universiti Malaysia Pahang for financial support (RDU 150333).

\section{References}

[1] Cho, S., Jeong, H., Park, D., Jung, S., Kim, H., Lee, K. (2010). The effects of vitamin C on $\mathrm{ZnO}$ crystal formation. CrystEngComm, 12: 968-976.

[2] Chaithanatkun, N., Chantarawong, D., Songkeaw, P., Onlaor, K., Thiwawong, T., Tunhoo, B. (2015). Effect of ascorbic acid on structural properties of $\mathrm{ZnO}$ nanoparticles prepared by precipitation process. 2015 IEEE 10th International Conference on Nano/Micro Engineered and Molecular Systems, NEMS 145-148.

[3] Zhang, Y., Wu, J., Aagesen, M., Liu, H. (2015). III - V nanowires and nanowire optoelectronic devices. J. Phys. D: Appl. Phys., 48: 463001.

[4] Chandore, V., Carpenter, G., Sen, R., Gupta, N. (2013). International Journal of Environmental Science: Development and Monitoring Synthesis of nano crystalline $\mathrm{ZnO}$ by $\mathrm{Mi}$ crowave Assisted Combustion method: An eco friendly and solvent free route. IJESDM, 4: 45-47.

[5] Zain, N.M., Stapley, A.G.F., Shama, G. (2014). Green synthesis of silver and copper nanoparticles using ascorbic acid and chitosan for antimicrobial applications. Carbohydrate Polymers, 112: 195-202.

[6] Hasanpoor, M., Aliofkhazraei, M., Delavari, H. (2015). Microwave-assisted Synthesis of Zinc Oxide Nanoparticles. Procedia Materials Science, 11: 320-325.

[7] Zhu, Y.J., Chen, F. (2014). Microwaveassisted preparation of inorganic nanostructures in liquid phase. Chemical Reviews, 114: 6462-6555.

[8] Thirumavalavan, M., Huang, K.-L., Lee, J.-F. (2013). Preparation and Morphology Studies of Nano Zinc Oxide Obtained Using Native and Modified Chitosans. Materials, 6: 41984212. 
[9] Rajendran, K., Sivalingam, T. (2013). Industrial method of cotton fabric finishing with chitosan - $\mathrm{ZnO}$ composite for anti-bacterial and thermal stability. Industrial Crops \& Products, 47: 160-167.

[10] Barreto, M.S.R., Andrade, C.T., Azero, E.G., Paschoalin, V.M.F., Aguila, E.M. Del (2017). Production of Chitosan / Zinc Oxide Complex by Ultrasonic Treatment with Antibacterial Activity. J. Bacteriol. Parasitol., 8 (330): 1-7.

[11] Farouk, A., Moussa, S., Ulbricht, M., Textor, T. (2012). ZnO Nanoparticles-Chitosan Composite as Antibacterial Finish for Textiles. International Journal of Carbohydrate Chemistry, 2012: 1-8.

[12] Sathiya, S.M., Okram, G.S., Dhivya, S.M., Manivannan, G., Rajan, M.A.J. (2016). ScienceDirect Interaction of Chitosan / Zinc Oxide Nanocomposites and their Antibacterial Activities with Escherichia coli. Materials Today: Proceedings, 3: 3855-3860.

[13] Abdelhady, M.M. (2012). Preparation and Characterization of Chitosan / Zinc Oxide Nanoparticles for Imparting Antimicrobial and UV Protection to Cotton Fabric. International Journal of Carbohydrate Chemistry, 2012: 16.

[14] Al-Naamani, L., Dobretsov, S., Dutta, J. (2016). Chitosan-zinc oxide nanoparticle composite coating for active food packaging applications. Innovative Food Science \& Emerging Technologies, 38: 231-237.

[15] Petkova, P., Francesko, A., Fernandes, M.M., Mendoza, E., Perelshtein, I., Gedanken, A., et al. (2014). Sonochemical Coating of Textiles with Hybrid $\mathrm{ZnO} /$ Chitosan Antimicrobial Nanoparticles. ACS Appl. Mater. Interfaces, 6: 1164-1172.

[16] Singh, G., Surinder, D. (2014). Facile fabrication and characterization of chitosan-based zinc oxide nanoparticles and evaluation of their antimicrobial and antibiofilm activity. International Nano Letters, 4: 1-11.

[17] Shahraki, R.R., Ebrahim, S.A.S., Masoudpanah, S.M. (2015). Synthesis and Characterization of Superparamagnetic Zinc Ferrite Chitosan Composite Nanoparticles. J. Supercond. Nov. Magn., 28: 2143-2147.

[18] Rinaudo, M. (2006). Chitin and chitosan: Properties and applications. Progress in Polymer Science, 31: 603-632.

[19] Niranjan, R., Koushik, C., Saravanan, S., Moorthi, A., Vairamani, M., Selvamurugan, N. (2013). International Journal of Biological Macromolecules A novel injectable temperature-sensitive zinc doped chitosan /glycerophosphate hydrogel for bone tissue engineering. International Journal of Biological Macromolecules, 54: 24-29.
[20] Perelshtein, I., Ruderman, E., Perkas, N., Tzanov, T., Beddow, J., Joyce, E., et al. (2013). Chitosan and chitosan-ZnO-based complex nanoparticles: formation, characterization, and antibacterial activity Antibacterial Activity. Journal of Material Chemistry B, 1: 1968-1976

[21] Guo, L., Yang, S., Bay, C.W., Kong, H., Yang, C., Yu, P., et al. (2000). Synthesis and Characterization of Poly(vinylpyrrolidone) Modified Zinc Oxide Nanoparticles. Chemistry Material. 12: 2268-2274.

[22] Mahmudin, L., Suharyadi, E., Bambang, A., Utomo, S. (2016). Influence of Stabilizing Agent and Synthesis Temperature on the Optical Properties of Silver Nanoparticles as Active Materials in Surface Plasmon Resonance (SPR) Biosensor Applications. Journal of Modern Physics. 6: 1071-1076

[23] Al-Gaashani, R., Radiman, S., Tabet, N., Daud, A.R. (2011). Effect of microwave power on the morphology and optical property of zinc oxide nano-structures prepared via a microwave-assisted aqueous solution method. Materials Chemistry and Physics, 125: 846852.

[24] Regiel-futyra, A., Sebastian, V., Irusta, S., Arruebo, M., Kyzio, A. (2015). Development of Noncytotoxic Chitosan-Gold Nanocomposites as Efficient Antibacterial Materials. ACS Appl. Mater. Interfaces. 7(2):1087-1099

[25] Sultan, N.M., Johan, M.R. (2014). Synthesis and Ultraviolet Visible Spectroscopy Studies of Chitosan Capped Gold Nanoparticles and Their Reactions with Analytes. The Scientific World Journal. 2014: 1-7

[26] Umer, A., Naveed, S., Ramzan, N. (2014). A green method for the synthesis of Copper Nanoparticles using L-ascorbic acid. Revista Materia, 19: 197-203.

[27] Pandiselvi, K., Thambidurai, S. (2015). Materials Science in Semiconductor Processing Synthesis , characterization, and antimicrobial activity of chitosan - zinc oxide / polyaniline composites. Materials Science in Semiconductor Processing, 31: 573-581.

[28] Khan, A., Mehmood, S., Sha, M., Yasin, T. (2013). Structural and antimicrobial properties of irradiated chitosan and its complexes with zinc. Radiation Physics and Chemistry, 91: 138-142.

[29] Rama, V., Priya Dharsini, G.R., Menaga, P.C., Usha, J.R.J. (2014). Synthesis and Characterization of Chitosan-Zinc Oxide Nanocomposite and its Antimicrobial Activity. The International Journal of Science \& Technoledge, 2: 137-140 
[30] Wang, X., Zheng, J., Fu, R., Ma, J. (2011). Effect of Microwave Power and Irradiation Time on the Performance of Pt/C Catalysts Synthesized by Pulse-microwave Assisted Chemical Reduction. Chinese Journal of Catalysis, 32: $599-605$.

[31] Wojnarowicz, J., Chudoba, T., Gierlotka, S., Lojkowski, W. (2018). Effect of microwave radiation power on the size of aggregates of $\mathrm{ZnO}$ NPs prepared using microwave solvothermal synthesis. Nanomaterials (Basel), 8: 1-17.

[32] Marsalek, R. (2014). Particle size and Zeta Potential of ZnO. Procedia - Social and Behavioral Sciences, 9: 13-17.

[33] Steffy, K., Shanthi, G., Maroky, A.S., Selvakumar, S. (2018). Journal of Infection and Public Health Enhanced antibacterial effects of green synthesized $\mathrm{ZnO}$ NPs using Aristolochia indica against Multi-drug resistant bacterial pathogens from Diabetic Foot Ulcer. Journal of Infection and Public Health, 11: 463-471.

[34] Elizabeth, M., Mohan, J.C., Manzoor, K., Nair, S. V, Tamura, H., Jayakumar, R. (2010). Folate conjugated carboxymethyl chitosan manganese doped zinc sulphide nanoparticles for targeted drug delivery and imaging of cancer cells. Carbohydrate Polymers, 80: 442448.

[35] El-naggar, M.E., Shaheen, T.I., Fouda, M.M.G., Hebeish, A.A. (2016). Eco-friendly microwave-assisted green and rapid synthesis of well-stabilized gold and core - shell silver gold nanoparticles. Carbohydrate Polymers, 136: 1128-1136.

[36] Jafarirad, S., Mehrabi, M., Divband, B., Kosari-nasab, M. (2016). Biofabrication of zinc oxide nanoparticles using fruit extract of Rosa canina and their toxic potential against bacteria: A mechanistic approach. Materials Science \& Engineering C, 59: 296-302.
[37] Wangoo, N., Kaushal, J., Bhasin, K.K., Mehta, S.K., Suri, C.R. (2010). Zeta potential based colorimetric immunoassay for the direct detection of diabetic marker $\mathrm{HbA} 1 \mathrm{c}$ using gold nanoprobes. Chem. Commun. 46: 57555757

[38] Yamamoto, O. (2001). Influence of particle size on the antibacterial activity of zinc oxide. International Journal of Inorganic Materials. 3: 643-646.

[39] Sirelkhatim, A., Mahmud, S., Seeni, A., Kaus, N.H.M., Ann, L.C., Bakhori, S.K.M., Hasan, H., Mohamad, D. (2015). Review on zinc oxide nanoparticles: Antibacterial activity and toxicity mechanism. Nano-Micro Letters, 7: 219242.

[40] Jin, T., Sun, D., Su, J.Y., Zhang, H., Sue, H.J. (2009). Antimicrobial Efficacy of Zinc Oxide Quantum Dots against Listeria monocytogenes, Salmonella Enteritidis, and Escherichia coli O157 : H7. Journal of Food Science, 4 (1): 46-52

[41] Premanathan, M., Karthikeyan, K., Jeyasubramanian, K., Manivannan, G. (2011). Selective toxicity of $\mathrm{ZnO}$ nanoparticles toward Gram-positive bacteria and cancer cells by apoptosis through lipid peroxidation. Nanomedicine: Nanotechnology, Biology, and Medicine, 7: 184-192.

[42] Mai-Prochnow, A., Clauson, M., Hong, J., Murphy, A.B. (2016). Gram positive and Gram negative bacteria differ in their sensitivity to cold plasma. Scientific Reports. 6: 38610 .

[43] Su, C., Sun, C., Juan, S., Hu, C., Ket, W., Sheut, M. (1997). Fungal mycelia as the source of chitin and polysaccharides and their applications as skin substitutes. 18: 11691174 .

[44] Padmavathy, N., Vijayaraghavan, R. (2008). Enhanced bioactivity of $\mathrm{ZnO}$ nanoparticlesan antimicrobial study. Science and Technology of Advanced Materials, 9(3): 035004

Selected and Revised Papers from The $4^{\text {th }}$ International Conference of Chemical Engineering \& Industrial Biotechnology (ICCEIB 2018) (http://icceib.ump.edu.my/index.php/en/) (Universiti Malaysia Pahang, by 1 1t_-2nd August 2018) after Peer-reviewed by Scientific Committee of ICCEIB 2018 and Peer-Reviewers of Bulletin of Chemical Reaction Engineering \& Catalysis 